\title{
Evaluación de un medio de cultivo para el aislamiento selectivo de campylobacters termotolerantes
}

\section{Evaluation of a culture medium for the selective isolation of thermotolerant campylobacters}

\author{
Álvaro Tresierra-Ayala, Juan Huanaquiri, Ramsés Perea, María Bendayán. \\ Laboratorio de Microbiología. Centro de Investigación de Recursos Naturales, Universidad Nacional de la \\ Amazonía Peruana. Psje. Los Paujiles S/N, San Lorenzo, distrito de San Juan Bautista, lquitos-Perú.
}

DOI: https://doi.org/10.33017/RevECIPeru2014.0004/

\section{Resumen}

Se evaluó la capacidad de aislamiento selectivo de un medio de cultivo para campylobacters termotolerantes, el cual fue suplementado con sangre de porcino y agentes restrictivos (sales biliares, tioglicolato de sodio, fucsina básica), en lugar de la sangre de ovino o equino y diversos antibióticos que suelen ser componentes de los medios comúnmente empleados. Se logró aislar e identificar 20 cepas (13 de Campylobacter jejuni y 7 de Campylobacter coli) de un total de 70 muestras, determinándose que no había diferencia estadísticamente significativa respecto a la capacidad de aislamiento entre el medio de cultivo evaluado y el medio Skirrow modificado. Para el análisis comparativo de la cuantificación del crecimiento de las cepas en ambos medios, se empleó la técnica de Miles y Misra modificada [1] y se observó que las cepas no mostraban diferencia estadísticamente significativa en cuanto a su crecimiento en los medios ensayados, obteniéndose recuentos promedios de $23,4 \times 10^{6}$ y $21,7 \times 10^{6} \mathrm{UFC} / \mathrm{ml}$, para la especie de $C$. coli en el medio de cultivo evaluado y el medio Skirrow modificado y de $44,6 \times 10^{6}$ y $40,1 \times 10^{6} \mathrm{UFC} / \mathrm{ml}$ para la especie $C$. jejuni en ambos medios de cultivo, respectivamente. El medio de cultivo evaluado permite la misma capacidad de aislamiento selectivo para campylobacters termotolerantes que el medio Skirrow modificado; además, estos agentes microbianos crecen cuantitativamente de modo similar en ambos medios de cultivo.

Descriptores: Campylobacter, medio de cultivo, sangre de porcino, sales y colorantes.

\begin{abstract}
The ability of selective isolation of a culture medium for thermotolerant campylobacters, supplemented with pig blood and restrictive agents (bile salts, sodium thioglycollate, basic fuchsin), instead of the blood of sheep or horses and various antibiotics which are often components of the means commonly employed was evaluated. Twenty strains (13 C. coli y $7 \mathrm{C}$. jejuni) were isolated and identified from a total of 70 samples There was not significant difference with respect to the isolation ability between the culture medium evaluated and the modified Skirrow medium. For the comparative analysis about quantification of the growth of strains in both media, Miles and Misra technique, modified [1], was employed. So, it was determined that the strains showed no significant difference with respect to their growth on both media studied. Average growth of $23,4 \times 10^{6}$ and $21,7 \times 10^{6} \mathrm{CFU} / \mathrm{ml}$ for $C$. coli in culture medium evaluated and the modified Skirrow medium, and 44,6 $\times 10^{6}$ and $40,1 \times 10^{6} \mathrm{CFU} / \mathrm{ml}$ for $C$. jejuni in both culture media, respectively, were detected. Culture medium evaluated allows the same ability selective isolation of thermotolerant campylobacter than modified Skirrow medium; moreover, these microbial agents grow similarly quantitatively in both culture media.
\end{abstract}


Keywords: Campylobacter, culture medium, blood pig, salts and dyes.

\section{Introducción}

Las bacterias termotolerantes del género Campylobacter, se caracterizan por ser bacilos curvos Gram negativos, de crecimiento lento, microaerófílos, cuya temperatura óptima de crecimiento es de $42^{\circ} \mathrm{C}$ (termotolerantes) y se les considera microorganismos nutricionalmente exigentes [2].

Entre estos seres microscópicos, $C$. jejuni y $C$. coli se han mostrado como unos de los más importantes agentes etiológicos de enteritis y en ocasiones de infección generalizada $u$ otras patologías [3]. Algunos investigadores responsabilizaron a estos agentes como la causa del $23 \%$ de cuadros diarreicos producidos a niños de la ciudad de lquitos [4]. Sin embargo, los laboratorios de análisis clínicos de la región amazónica no incluyen en el coprocultivo rutinario la búsqueda de estos agentes; lo cual podría deberse, entre muchas razones, al elevado costo del análisis y a la dificultad de preparación de los medios de cultivo empleados para el aislamiento de los campylobacters.

En esta región, resulta dificultoso agenciarse de sangre de ovino o equino (componente de la mayoría de medios de cultivo para estos agentes), ya que su crianza es escasa y tomando como base los estudios realizados por algunos investigadores [5, 6[, se plantea la posibilidad de utilizar otras fuentes abundantes de sangre, en vez de la de ovino o equino, que son difíciles de conseguir.

El empleo de sales y colorantes, en reemplazo de la mezcla de antibióticos empleada en todos los medios para campylobacters, facilitaría su proceso de preparación, Este hecho disminuiría el precio de estos medios de aislamiento y de este modo, los laboratorios de análisis clínicos podrían incluir la búsqueda de estos enteropatógenos al realizar los coprocultivos rutinarios.Es así que el objetivo del presente estudio fue evaluar la capacidad de aislamiento selectivo de un medio de cultivo para campylobacters termotolerantes, el cual fue suplementado con sangre de porcino y agentes restrictivos (sales y colorante).

\section{Materiales y Métodos}

Setenta muestras del contenido intestinal de aves de corral (55 pollos y 15 patos), de la ciudad de lquitos, obtenidas mediante la técnica del hisopado cloacal, fueron depositadas en tubos con medio de transporte y enriquecimiento selectivo para Campylobacter [7], para su análisis respectivo. Posteriormente, estas fueron sembradas tanto en placas con agar Skirrow modificado como con el medio de cultivo evaluado $(3 \mathrm{mg} / \mathrm{L}$ de sales biliares, $5 \mathrm{mg} / \mathrm{L}$ de tioglicolato de sodio y $2 \mathrm{mg} / \mathrm{L}$ de fucsina básica), e incubadas bajo condiciones de microaerofilia a $42{ }^{\circ} \mathrm{C}$ durante $48 \mathrm{~h}$. A las colonias con características sospechosas de pertenecer al género Campylobacter, se les realizó pruebas para la identificación presuntiva (características de la colonia, morfología celular, prueba de la catalasa y oxidasa), y posteriormente, pruebas para la identificación confirmativa (hidrólisis del hipurato y sensibilidad al ácido nalidíxico) [8].

Las cepas identificadas como campylobacters termotolerantes, fueron sembradas, por duplicado, en el medio Skirrow modificado y medio de cultivo evaluado, mediante la técnica de microrrecuento de Miles y Misra modificada [1], para determinar la capacidad de crecimiento de las cepas de Campylobacter termotolerantes

\section{Resultados}

De las 70 muestras procesadas, 20 (28,6\%) resultaron positivas para especies de Campylobacter termotolerantes (Tabla $N^{\circ} 1$ ). Además, se observó que el porcentaje de aislamiento más alto se obtuvo en las muestras procedentes de pollos $(29,1 \%)$, mientras que las muestras obtenidas de patos mostraron un $26,7 \%$ de positividad. También se pudo apreciar que la especie más frecuentemente aislada fue $C$. jejuni (18,6\%); mientras que $C$. coli se aisló en menor frecuencia $(10,0 \%)$. En pollos y patos, la especie más frecuentemente aislada fue $C$. jejuni $(18,2 \%$ y $20.0 \%$, respectivamente), mientras que la de menor frecuencia fue $C$. coli $(10,9 \%$ y $6.7 \%$, respectivamente).

De las 20 muestras positivas detectadas en el agar Skirrow modificado, sólo 16 fueron consideradas como tales en el medio propuesto (Tabla $\mathrm{N}^{\circ} 2$ ), diferencia que no fue estadísticamente significativa $(p \geq 0.05)$. Cabe señalar, que ambos medios permitieron aislar la totalidad de cepas de C. coli; sin embargo, el medio de cultivo evaluado, a diferencia del Skirrow modificado en el que se aisló la totalidad de cepas, sólo permitió aislar el $69,2 \%$ de cepas de C. jejuni. De acuerdo al análisis estadístico 
realizado, esta diferencia no fue significativa $(p \geq 0,05)$.

La tabla $\mathrm{N}^{\circ} 3$ muestra los promedios de las dos repeticiones que se obtuvieron del recuento de UFC/ml, al comparar la capacidad de crecimiento de las 20 cepas de Campylobacter, previamente aisladas, en el medio de cultivo propuesto y el medio Skirrow modificado. Se puede observar que las 20 cepas crecieron en ambos medios, con una ligera diferencia entre ellos, la cual resultó no ser estadísticamente significativa $(p \geq 0.05)$. De igual modo, sucedió con el crecimiento a nivel de especies.

\section{Discusión}

Las 20 cepas de Campylobacter fueron aisladas de aves de corral, para lo cual fue necesario muestrear a 70 especímenes, esto equivale a una tasa de aislamiento de 28,6\%, valor que es menor al registrado por Bernuy \& Pereyra [9], quienes reportaron una tasa de aislamiento de 39,0\% en aves de corral de la ciudad de lquitos. Estas bacterias fueron aisladas del $29,1 \%$ de pollos, porcentaje que resultó ser notoriamente menor con respecto al 54,0\% registrado en 1994 [9]; sin embargo, los porcentajes de aislamiento a partir de patos, tanto en este estudio como en el anterior, fueron muy similares.

En cuanto al análisis comparativo de la capacidad de aislamiento de Campylobacter termotolerantes entre el medio de cultivo evaluado y el medio Skirrow modificado, se observó que ambos permitían el aislamiento selectivo de estas bacterias, puesto que de las 70 muestras analizadas, el medio de Skirrow modificado permitió aislar 20 cepas de Campylobacter termotolerantes mientras que el medio de cultivo evaluado permitió aislar sólo a 16 de estas; sin embargo, dicha diferencia resultó no ser estadísticamente significativa. ( $p \geq 0.05)$.

Cabe destacar la acción restrictiva producida por los agentes antimicrobianos empleados en la composición del medio de cultivo propuesto (sales biliares, tioglicolato de sodio y fucsina básica), sin embargo, sus concentraciones no eran suficientes para restringir el crecimiento de todos los agentes bacterianos presentes en el contenido intestinal de las aves muestreadas. Teniendo en consideración que estos agentes son compuestos químicos que se utilizan con fines de aislamiento selectivo, mayormente para bacterias Gram negativas, como las enterobacterias $y$ otras de importancia microbiológica, es aceptable pensar que estos microorganismos se encuentren en el contenido intestinal de las aves y por consiguiente, crezcan en medios de cultivo que tienen este tipo de agentes.

Se podría pensar, que aumentando los valores de las concentraciones de los agentes restrictivos utilizados en el medio propuesto se podría lograr mejorar la capacidad de aislamiento de dicho medio; pero el incrementar 10 veces la concentración de los colorantes del trifenilmetano podría inhibir el crecimiento de la propia bacteria que se desea aislar y por tanto, esta no se aislaría [10]. Este hecho también lo observaron Adrianzén \& Alava [3], puesto que determinaron que concentraciones de sales biliares, fucsina básica y tioglicolato de sodio, superiores a las empleadas en el presente estudio, inhibían el crecimiento tanto de $C$. jejuni como de $C$. coli. Por otro lado, es una regla general el hecho que los microorganismos Gram positivos son más susceptibles a estos compuestos que los Gram negativos [10].

Tabla 1: Aislamiento y distribución de las especies termotolerantes de Campylobacters en aves de corral

\begin{tabular}{|c|c|c|c|c|c|c|c|}
\hline \multirow{3}{*}{ AVES DE CORRAL } & \multirow{3}{*}{ № } & \multicolumn{4}{|c|}{ ESPECIE } & \multirow{2}{*}{\multicolumn{2}{|c|}{ TOTAL }} \\
\hline & & \multicolumn{2}{|c|}{ C. jejuni } & \multicolumn{2}{|c|}{ C. coli } & & \\
\hline & & № & $\%$ & № & $\%$ & № & $\%$ \\
\hline $\begin{array}{l}\text { POLLOS } \\
\text { PATOS }\end{array}$ & $\begin{array}{l}55 \\
15\end{array}$ & $\begin{array}{c}10 \\
3\end{array}$ & $\begin{array}{l}18.2 \\
20.0\end{array}$ & $\begin{array}{l}6 \\
1\end{array}$ & $\begin{array}{r}10.9 \\
6.7\end{array}$ & $\begin{array}{r}16 \\
4\end{array}$ & $\begin{array}{l}29.1 \\
26.7\end{array}$ \\
\hline TOTAL & 70 & 13 & 18.6 & 7 & 10.0 & 20 & 28.6 \\
\hline
\end{tabular}


Tabla 2: Capacidad de aislamiento de las cepas de Campylobacter termotolerantes en el medio de cultivo Skirrow modificado y el medio de cultivo evaluado.

\begin{tabular}{|c|c|c|c|}
\hline \multirow{2}{*}{ № de Cepa } & \multirow{2}{*}{ Especie } & \multicolumn{2}{|c|}{ Aislamiento en } \\
\hline & & $\begin{array}{l}\text { Skirrow } \\
\text { Modificado }\end{array}$ & $\begin{array}{c}\text { Medio } \\
\text { Evaluado }\end{array}$ \\
\hline $1,2,3,4,5,6,7$ & C. coli & + & + \\
\hline $8,9,10,12,13,15,17,18,20$ & C. jejuni & + & + \\
\hline $11,14,16,19$ & C. jejuni & + & - \\
\hline \multicolumn{2}{|c|}{ № / \% de cepas aisladas de 20 muestras positivas } & $20 / 100$ & $16 / 80$ \\
\hline \multicolumn{2}{|c|}{$\mathrm{N}^{\circ} / \%$ de cepas de $C$. coli aisladas de 7 muestras positivas } & $7 / 100$ & $7 / 100$ \\
\hline $\begin{array}{l}\mathrm{N}^{\circ} / \% \text { de cepas de } C . j \\
\text { positivas }\end{array}$ & de 13 muestras & $13 / 100$ & $9 / 69.2$ \\
\hline
\end{tabular}

$p \geq 0.05$

Tabla 3: Número de UFC/ml de las cepas de Campylobacter termotolerantes de acuerdo al medio de cultivo empleado

\begin{tabular}{|c|c|c|c|}
\hline \multirow{2}{*}{ № de Cepa } & \multirow{2}{*}{ Especie } & \multicolumn{2}{|c|}{ Medios de Cultivo } \\
\cline { 3 - 4 } & C. coli & $36 \times 10^{6}$ & Skirrow Modificado \\
\hline 1 & C. coli & $14 \times 10^{6}$ & $17 \times 10^{6}$ \\
\hline 2 & C. coli & $20 \times 10^{6}$ & $20 \times 10^{6}$ \\
\hline 3 & C. coli & $20 \times 10^{6}$ & $20 \times 10^{6}$ \\
\hline 4 & C. coli & $30 \times 10^{6}$ & $20 \times 10^{6}$ \\
\hline 5 & C. coli & $22 \times 10^{6}$ & $30 \times 10^{6}$ \\
\hline 6 & C. coli & $10 \times 10^{6}$ & $30 \times 10^{6}$ \\
\hline 7 & C. jejuni & $80 \times 10^{6}$ & $90 \times 10^{6}$ \\
\hline 8 & C. jejuni & $70 \times 10^{6}$ & $100 \times 10^{6}$ \\
\hline 9 & C. jejuni & $90 \times 10^{6}$ & $90 \times 10^{6}$ \\
\hline 10 & C. jejuni & $10 \times 10^{6}$ & $20 \times 10^{6}$ \\
\hline 11 & C. jejuni & $30 \times 10^{6}$ & $30 \times 10^{6}$ \\
\hline 12 & C. jejuni & $29 \times 10^{6}$ & $33 \times 10^{6}$ \\
\hline 13 & C. jejuni & $30 \times 10^{6}$ & $20 \times 10^{6}$ \\
\hline 14 & C. jejuni & $60 \times 10^{6}$ & $100 \times 10^{6}$ \\
\hline 15 & C. jejuni & $40 \times 10^{6}$ & $40 \times 10^{6}$ \\
\hline 16 & C. jejuni & $16 \times 10^{6}$ & $16 \times 10^{6}$ \\
\hline 17 & C. jejuni & $11 \times 10^{6}$ & $6 \times 10^{6}$ \\
\hline 18 & C. jejuni & $5 \times 10^{6}$ & $5 \times 10^{6}$ \\
\hline 19 & C. jejuni & $50 \times 10^{6}$ & $30 \times 10^{6}$ \\
\hline 20 & & & \\
\hline
\end{tabular}

$p \geq 0.05$

Algunos investigadores [1,11.12]; han sugerido que las cepas de $C$. coli suelen ser más resistentes a antimicrobianos y a condiciones ambientales adversas que las de $C$. jejuni. Este hecho también fue observado en el presente estudio, toda vez que el medio propuesto permitió aislar a todas las cepas de $C$. coli estudiadas, mas no a las de $C$. jejuni, cuyo aislamiento se vio dificultado probablemente debido a un escaso crecimiento de las mismas o tal vez a un enmascaramiento del 
crecimiento de las colonias de $C$. jejuni por la presencia de otros contaminantes (Tabla № 2).

En cuanto al análisis comparativo de la capacidad de crecimiento de las 20 cepas de Campylobacter termotolerantes entre el medio de cultivo propuesto y el medio de Skirrow modificado (Tabla № 3), se observó que no existe diferencia significativa $(p \geq 0.05)$ respecto a la capacidad de crecimiento cuantitativo de las cepas en ambos medios, a pesar que 4 de las cepas de $C$. jejuni $\left(\mathrm{N}^{\circ} 11,14\right.$, 16 y 19), no fueron aisladas en el medio propuesto (Tabla № 2), lo cual indica que esto se debía probablemente a la dificultad de aislamiento de dichas cepas causada por el enmascaramiento por parte de colonias contaminantes, posiblemente de Gram negativos y no, por la incapacidad de crecimiento de dichas cepas. Para evitar esto, sería conveniente ensayar otros agentes que tengan efecto restrictivo sobre estas bacterias contaminantes Gram negativas, capaces de crecer en el medio propuesto, pero que a su vez, no afecten el normal crecimiento de las especies termotolerantes de Campylobacter.

\section{Conclusiones}

El medio de cultivo propuesto permite la misma capacidad de aislamiento selectivo de Campylobacter termotolerantes que el medio de Skirrow modificado.

Las cepas de Campylobacter termotolerantes crecen cuantitativamente, de modo similar, en el medio de cultivo propuesto y en el medio de cultivo Skirrow modificado.

\section{Referencias}

[1] A. Tresierra-Ayala, R. Ruiz, M. Bendayán. $H$. Fernández. Survival times of Campylobacter coli in sterilized buffalo milk. J. Vet. Med. B. (1999), 46: 141-144.

[2] F. Hernández. Cultivo de bacterias microaerofílicas: Campylobacter. Rev. Col. de MQC de Costa Rica. (2002), 8: 48-54.

[3] P. Adrianzén, F. Alava. Efecto de algunas sales y colorantes sobre elcrecimiento de Campylobacter coli y Campylobacter jejuni subsp. jejuni. Tesis para optar el Título Profesional de Biólogo. Universidad Nacional de la Amazonia Peruana. Iquitos. 54.

[4] O. Grados, N. Bravo,N. BLACK, et al. 1988. Paediatric Campylobacter diarrhoea from household exposure to live chickens in Lima, Peru. Boll. WHO. (1988), 66: 369-374.

[5] C. Anand, G. Rhonda,S. Helene, K. Fonseca, M. Olsen. Pig and goat blood as substitutes for sheep blood in bloodsupplemented agar media. J Clin Microbiol, (2000), 38: 591-594.

[6] J. Flores, M. Navas. Uso de la sangre de vacuno y porcino para el crecimiento de Campylobacter termotolerantes e influencia de $\mathrm{pH}$ del medio sobre su capacidad hemolitica. Tesis para optar el Titulo Profesional de Biólogo. Universidad Nacional de la Amazonia Peruana. (2008): 43.

[7] A. Tresierra-Ayala, M. Bendayán, A. Bernuy, G. Pereyra and H. Fernández. Chicken as potential contamination source of Campylobacter lari in lquitos, Peru.Rev.Inst.Med.Trop.Sao Paolo, (1994), 36: $497-499$.

[8] H. Lior. New extended biotyping scheme for Campylobacter jejuni, Campylobacter coli and Campylobacter laridis.

J.Clin.Microbiol.(1984), 20: 636-640.

[9] A. Bernuy, G. Pereyra. Campylobacter termotolerantes en aves de corral de la ciudad de lquitos. Tesis para optar el Titulo Profesional de Biólogo. Universidad Nacional de la Amazonía Peruana. (1994). 52.

[10] G. Pelczar et al. Microbiología. Segunda edición. Editorial Mc GRAW HILL. México. (1982): 826.

[11] G. Prats, B. Mirelis, T. LLovet, C. Muñoz, E. Miró, F. Navarro. Antibiotic resistance trends in enteropathogenic bacteria isolated in 1985-87 and 1995-98 in Barcelona.

Antimicrobial Agents and Chemotherapy (2000), 44: 1144-1145.

[12] M. Aquino, A. Filgueiras, M. Ferreyra, S. Oliveira, M. Bastos, A. Tibana, Antimicrobial resistance and plasmid profiles of Campylobacter jejuni and Campylobacter coli from human and animal sources. Letters in Applied Microbiology (2002), 34: 149-153. 